\title{
Response of Microchemical Balances to changes in Relative Humidity
}

\author{
H. E. Almer
}

(June 9, 1960)

\begin{abstract}
The effects of relative humidity were investigated on four microchemical balances (two equal-arm two-pan and two one-pan direct reading).

Tests were begun by reading the balance indications at low relative humidities; humidified air was then introduced into the balance case and balance indication and hygrometer readings were taken as the moist air was gradually replaced by drier room air. Individual balance parts which were suspected of mass changes with relative humidity were separately weighed at controlled humidities by a balance operated in uniform, rather dry room air.

The balances all responded rapidly to changes in humidity and quickly reached new equilibria. All but one of the four balances - a one-pan balance - responded systematically. Largest changes in balance indication with humidity were found to be caused by hygroscopic materials used in construction. Foreign hygroscopic material on live parts of balances would be equally damaging.

The effects are not predictable even after balances of a given design have been studied, so in practice each balance should be tested. If changes with humidity are not negligible, hygroscopic materials must be removed as far as practicable. With a good balance, a small variation in humidity may be disregarded.
\end{abstract}

\section{Introduction}

Corwin ${ }^{1}$ made observations on the effect of change in relative humidity on two types of balances and on the effect of moisture absorbed by the bearings. ${ }^{2}$ With equilibrium established at each humidity level, he observed as much as $0.015-\mathrm{mg}$ change in zero point, which he ascribed mainly to unsymmetric absorption of water by the bearings. From his studies, and from the author's own observations during precision weighings, it appears that the effect of fluctuations in humidity are not always negligible.

The purpose of this paper is to describe experiments designed to confirm the measurability of the effect of change in relative humidity on operation and to study them. The aim was not to determine quantitatively the physical relationships involved, since such relationships would vary with balance design, construction, and craftsmanship of the individual instruments, but rather to see whether high-precision balances of different design can ba so adjusted or corrected that effects of change of humidity become so small as to be negligible.

Four microchemical balances of $20-\mathrm{g}$ capacity were studied in the present investigation. Balances $\mathrm{A}$ and $\mathrm{B}$ were two-pan, equal-arm, balances, with balance B designed so that keyboard weights could be used. These two balances were made by dif-

\footnotetext{
${ }^{1}$ A. H. Corwin, Microchemical balances, errors of Kuhlman balance, Ind Eng. Chem., Anal. ed. 16, No. 4, p. 258 (Apr. 1944).

2 Bearing includes the combination of a knife edge and a plane.
}

ferent manufacturers. Balances $\mathrm{C}$ and $\mathrm{D}$ were one-pan, direct-reading balances. They were made by the same manufacturer, but balance $\mathrm{D}$ was a later model. Balance $\mathrm{D}$ differed from $\mathrm{C}$ in that it had a polished aluminum counterweight fastened to the beam with an aluminum bolt, whereas $\mathrm{C}$ had a brass counterweight and bolt; the compensating weight on the weight-hanger of balance D was sealed, whereas that of $\mathrm{C}$ was not; and balance $\mathrm{D}$ had a stainless steel pan, and $\mathrm{C}$ an aluminum one. All of the balances were damped.

Two ways in which a balance may be affected by changes in relative humidity are: By absorption of moisture by hygroscopic materials used in its construction, and by adsorption of moisture on the surfaces of the balance parts.

\subsection{Absorption}

Hygroscopic materials are used in the construction of many microchemical balances and other precision balances. Examples of such materials are: Coment, used to hold bearing planes in the stirrups; agate, used for pivots and bearings; and lacquer, used to coat parts of the balances. The amount of moisture absorbed by these materials varies with the relative humidity. This variation may adversely affect the performance of a balance, because the amounts of the hygroscopic materials may not be exactly equal on the two halves. Moreover, since the exposed surfaces will not be precisely similar, the rate of absorption will not be equal in the two halves of the balance. 


\subsection{Adsorption}

A thin film of moisture collects on the surfaces of the parts of a balance, its amount depending on the nature and area of the surface. Although changes in relative humidity cause changes in the amount of moisture adsorbed, inequality of behavior of the two balance halves is likely to be less for adsorbed than absorbed water.

The possibility of these effects affecting the behavior of a balance is greater with a one-pan balance than with an equal-arm, two-pan balance, because the one-pan balance is assymetrical.

\section{Experiment Procedure}

The temperature of the laboratory where the experiments were made was constant to within about $5{ }^{\circ} \mathrm{C}$. The relative humidity varied from about 20 percent in the winter to about 45 percent in the summer. These conditions helped in designing the tests.

Readings were first taken at the low relative humidity. Then the humidity in the balance case was artificially increased by introducing moist air. No attempt was made to hold the relative humidity at its maximum for any appreciable length of time. Gradually, the moist air leaked out and was replaced by the drier room air. The doors of balances $\mathrm{C}$ and D were opened a few times for 2 or $3 \mathrm{~min}$ so the drier room air could replace the moist air more rapidly. This caused the steplike decreases in relative humidity shown in figures 3 and 4 , and could account for some of the erratic behavior of the balances. Humidity and balance readings were taken sequentially, but as near together as practicable and the entire cycle described above was repeated two or three times with each balance. No readings of the balance indication were taken while the relative humidity was being raised because of the turbulence of the air within the balance case, nor were observations of the relative humidity recorded as it was being increased. Therefore the increases in relative humidity are shown as straight lines in the figures instead of as curves which level off as the relative humidity approaches a maximum.

Balance indication is the rest point of the balance, as given by the position of the indicator or pointer with reference to a scale, in terms of mass units, at the instant the observation was made.

To change the relative humidity inside the balance case, a small blower was used to circulate the air from the case into a can partly filled with water and back into the case. In this way the relative humidity could be increased to 75 or 80 percent.

The relative humidity inside the balance case was measured with an electric hygrometer. One set of sensing elements covering the range from 12 to 73 percent was used with the two-pan, equal-arm balances. Two sets of sensing elements covering the ranges from 10 to 96 percent and from 19 to 92 percent were used with the two-compartment, one-pan direct-reading balances.
To determine whether variation in relative humidity affected the mass of certain component parts of a balance, the parts were weighed at both high and low relative humidity, then cleaned, lacquer removed, and reweighed under similar conditions. A balance, not under test, and a closed chamber located directly under it were used for this part of the investigation. An auxiliary pan was suspended inside the chamber by a wire which was connected through a small hole in the top of the chamber to one of the balance pans. This arrangement was constructed so that the part under test could be put on or removed from the auxiliary pan without opening the chamber. The relative humidity inside the chamber could be changed as desired while the humidity of the air in the balance case remained the same as that in the laboratory. The part under test was placed in the chamber and weighed at both high and low relative humidities with the chamber closed. Test balances were reassembled and tested for variation with change in relative humidity.

To confirm that the variation in balance indication was not due to temperature gradients, the gradients within two of the balances under test were measured and controlled. Measurements were made with a potentiometer, using a spotlight galvanometer as a null indicator and thermopiles as sensing elements. The temperature gradients were controlled by lamps appropriately placed around the balances. The heat produced by the lamps was regulated by varying the voltage on the lamps.

The constancy of the temperature in the laboratory made it impracticable to investigate any effect of temperature changes on the response to change in relative humidity.

\section{Results of the Tests}

The results of the tests are illustrated in figures $1,2,3$, and 4 .

\subsection{Balance $\mathbf{A}$ (fig. 1)}

Balance A responded rapidly to changes in relative humidity and quickly reached a new equilibrium point with each change. The change in the rest point of the balance was about $2 \mu \mathrm{g}$ for each 1-percent change in relative humidity.

Temperature gradients, except the vertical one, were kept within $0.05^{\circ} \mathrm{C}$. The vertical temperature gradient increased when the moist air was introduced. Subsequent tests demonstrated that the effect was not caused by the increase in vertical temperature gradient.

\subsection{Balance B (fig. 2)}

This balance also responded rapidly, and quickly reached new equilibrium points. When the relative humidity was increased from about 49 percent to about 75 percent, the balance indication went off scale. 


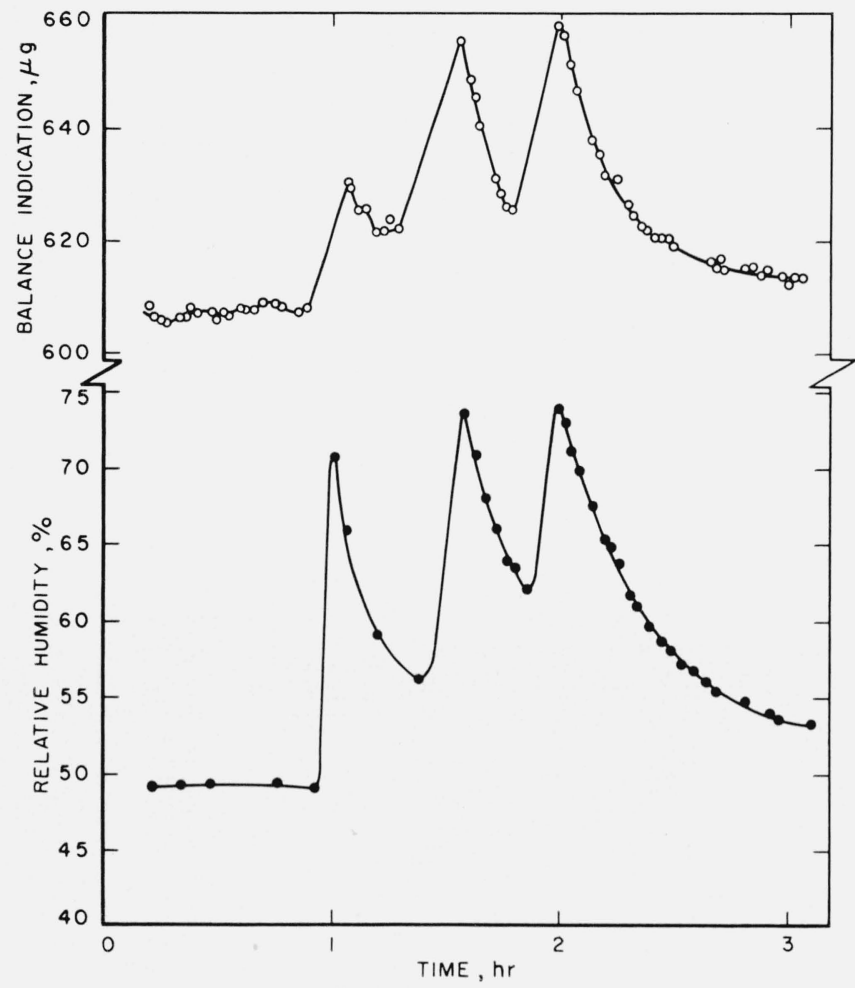

Figure 1. Response ofbalance A to change in relative humidity.

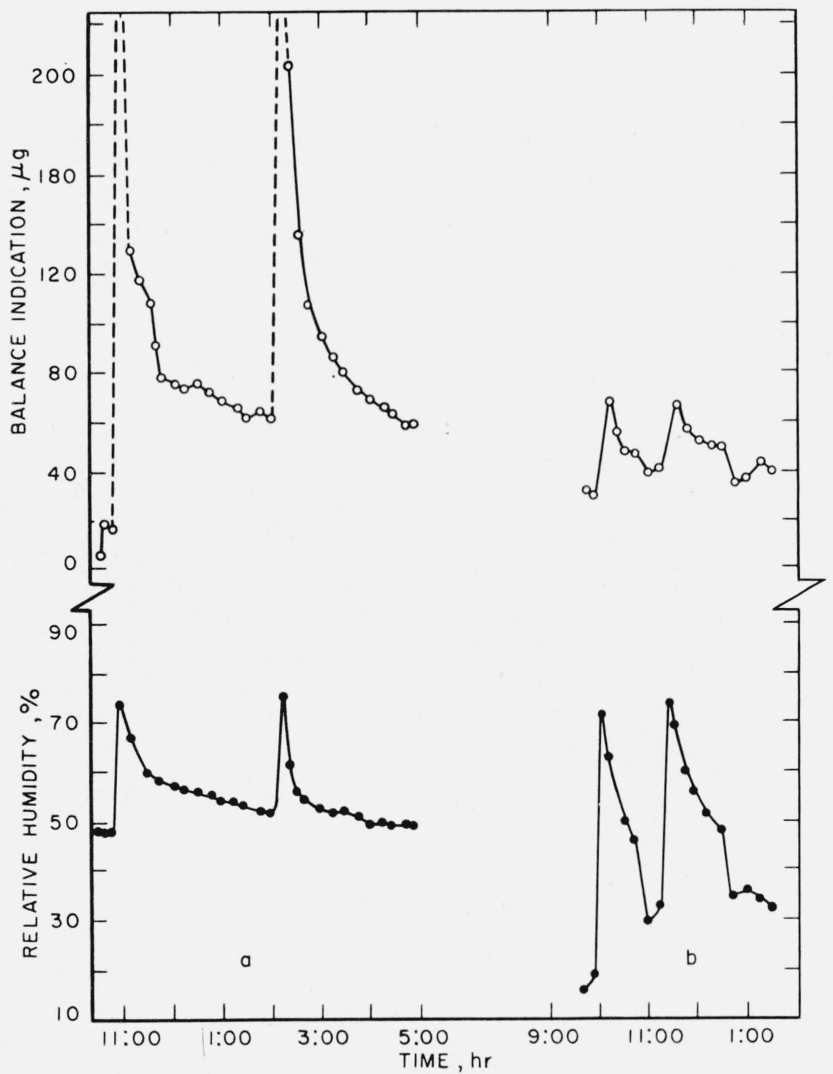

Figure 2. Response of balance $B$ to change in relative humidity.

a. Results of test before cleaning parts of the balance, removing lacquer and excess cement. b. Results of test after cleaning, removing lacquer and excess cement.
To determine the source of this large variation, the beam and both of the stirrups were tested for constancy before and after cleaning. The beam was tested without pans and stirrups in its normal position in the balance. The average change in indication observed before cleaning was about $4.3 \mu \mathrm{g}$ for each percent change in relative humidity; after cleaning this change decreased to about $3.1 \mu \mathrm{g}$. The stirrups were tested by weighing under controlled humidities. Results are given in table 1 .

TABLE 1. Maximum variation in mass with change in relative humidity

\begin{tabular}{|c|c|c|c|c|}
\hline \multirow{2}{*}{ Part } & \multicolumn{2}{|c|}{ As received } & \multicolumn{2}{|c|}{$\begin{array}{l}\text { After cleaning, removing } \\
\text { lacquer and excess cement }\end{array}$} \\
\hline & $\begin{array}{c}\text { Range of } \\
\text { change in } \\
\text { relative } \\
\text { humidity }\end{array}$ & $\underset{\mu \mathrm{g} / 1 \%}{\text { Variation }}$ & $\begin{array}{l}\text { Range of } \\
\text { change in } \\
\text { relative } \\
\text { humidity }\end{array}$ & $\begin{array}{l}\text { Variation } \\
\mu \mathrm{g} / 1 \%\end{array}$ \\
\hline $\begin{array}{l}\text { Stirrup 1--- } \\
\text { Stirrup 2--- }\end{array}$ & $\begin{array}{l}\% \\
26 \text { to } 84 \\
36 \text { to } 85\end{array}$ & $\mu \mathrm{g} \quad \begin{array}{r}2.5 \\
10.9\end{array}$ & $\begin{array}{l}\% \\
12 \text { to } 83 \\
32 \text { to } 71\end{array}$ & $\begin{array}{lr}\mu \mathrm{g} & \\
& 1.6 \\
& 2.4\end{array}$ \\
\hline
\end{tabular}

Because the above tests had located the major sources of the variation, it was not considered necessary to test other parts of the balance for mass. constancy. However, a consideration of the surface areas indicates that for clean parts the total amount of moisture gained or lost to probably be about 0.1 or $0.2 \mathrm{mg}$ per 1 percent change in relative humidity.

The balance was reassembled and again tested for behavior under varying humidity. The results are given in figure $2 \mathrm{~b}$. The change in indication was about $0.8 \mu \mathrm{g}$ for each 1-percent change in relative humidity. The temperature conditions were the same as with balance $\mathrm{A}$.

\subsection{Balance C (fig. 3)}

Balance $\mathrm{C}$ responded to changes in relative humidity as did balances A and B. The balance indication changed about $8.2 \mu \mathrm{g}$ for each 1-percent change in relative humidity. However, after the beam, weight suspension, pan, and bearing plate were cleaned, the change in indication dropped to about $2.8 \mu \mathrm{g}$ for each 1 -percent change in relative humidity. It was found that the bearing plate, when tested by itself, varied $0.5+\mu \mathrm{g}$ for each 1-percent change in relative humidity, and the weight suspension $1.9+\mu \mathrm{g}$ for each $1-$ percent change in relative humidity before cleaning. These parts were not tested individually after cleaning.

Temperatures gradients were not controlled nor measured during these tests.

\subsection{Balance D (fig. 4)}

This balance responded to changes in relative humidity as did the other balances. The change in balance indication for a 1-percent change in relative humidity was variable in amount and direction. Here again, the temperature gradients were not controlled nor measured. 


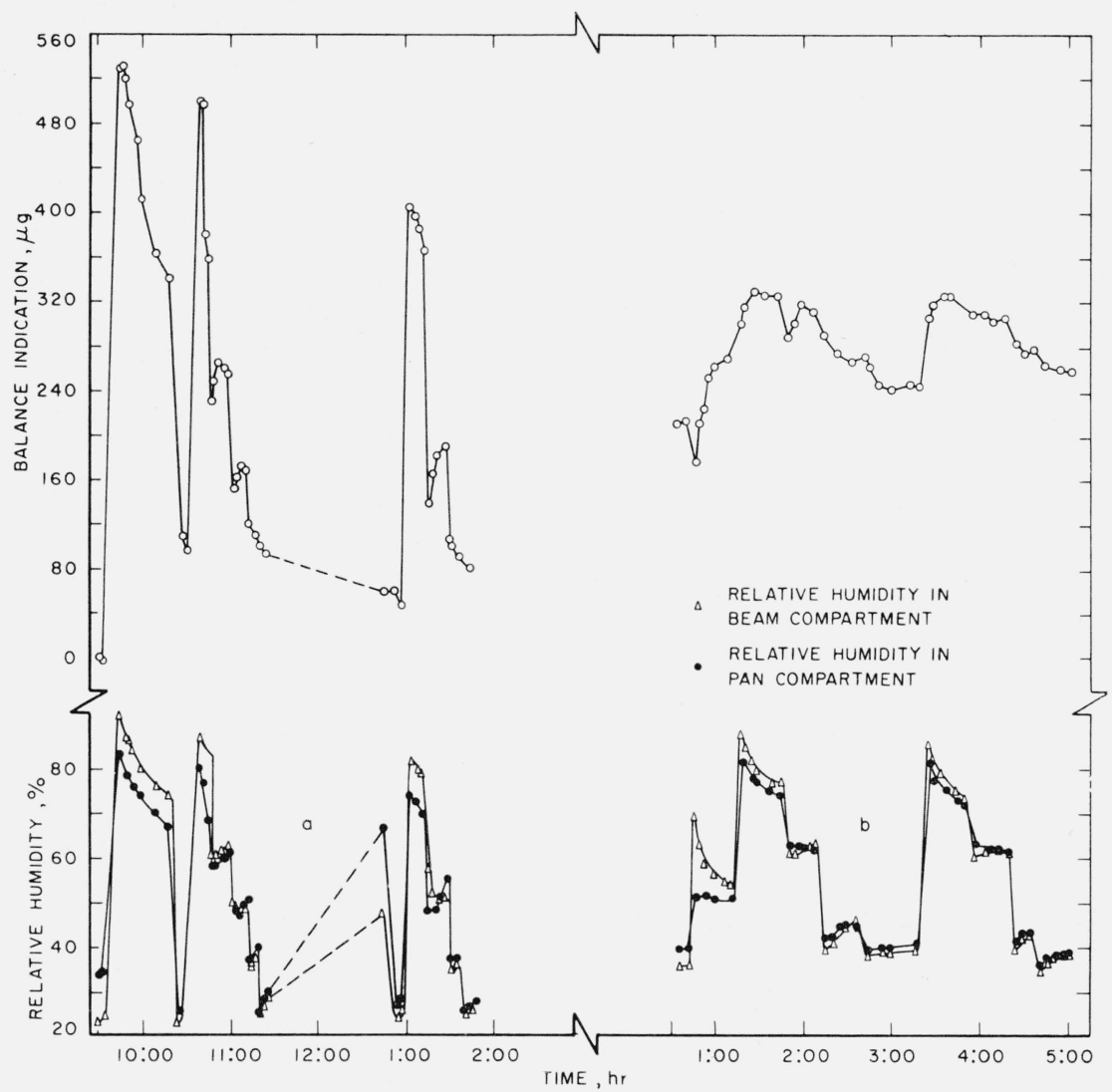

Figure 3. Response of balance $C$ to change in relative humidity.

a. Results of the test before cleaning parts of the balance. b. Results of the test after cleaning parts of the balance.

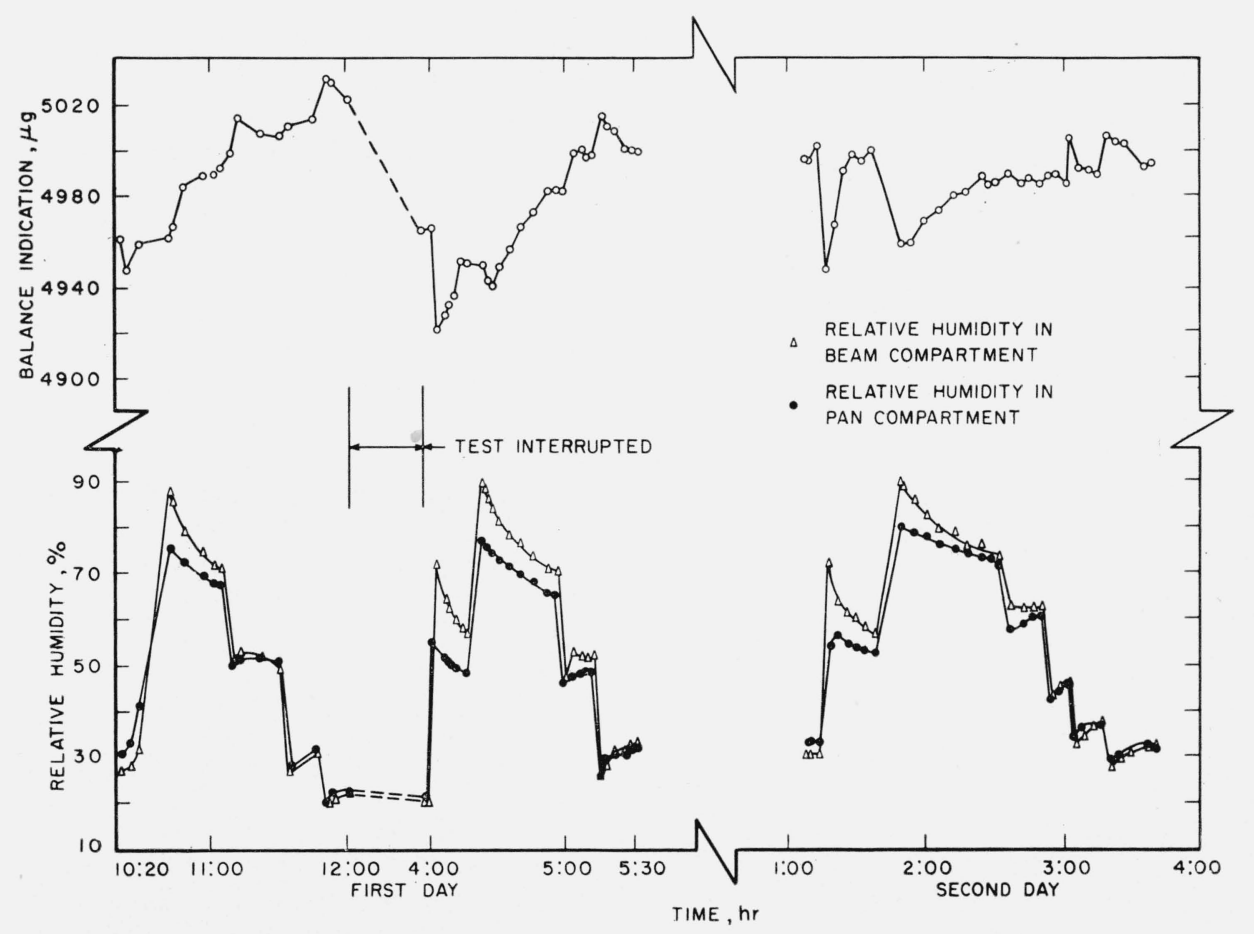

FICURE 4. Response of balance $D$ to changes in relative humidity.

The first test was interupted at noon and resumed about 4 p.m. The second part of the test was made the following day. 


\section{Discussion}

In the tests of balance $\mathrm{A}$, the systematic change in indication was tentatively ascribed to the lacquer on the beam, rather than to the agate bearings (see footnote 2) or to the cement, but a definite determination would have required destructive tests.

The systematic change in indication by balance B was caused largely by the lacquer on the keyboard weight carrier, which was attached to stirrup 2 . Before removing the lacquer, the mass of the stirrup and weight-carrier varied about $0.5 \mathrm{mg}$ for a 49 -percent change in relative humidity, but after removing the lacquer, the variation was less than $0.1 \mathrm{mg}$ for a 39 -percent change in relative humidity. Cement and lacquer on other parts also contributed to the change in balance indication. Furthermore, the inequality of surface areas on the two sides of the balance may have had an effect.

Balance $\mathrm{C}$ showed a systematic response to changes in relative humidity. A large part of the effect seemed to be caused by absorption of moisture by foreign material on the balance parts, since the response to change was only about one-third as large after cleaning the balance parts as before. The differences in the relative humidity in the two compartments of the balance may have been partially responsible. These differences were larger than usually found under ordinary laboratory conditions.

Balance D did not exhibit as marked a systematic response to changes in relative humidity as the other balances. This may have been due in part to design and construction details, such as the polished aluminum counterweight instead of the brass one in balance C. Some of the relatively large and seemingly erratic variations appear to have been caused by turbulence within the balance because most were observed immediately after moist air was introduced or the door opened. Balance D also had two compartments and the differences in their relative humidities may have had some effect.

The response of the balances to changes in relative humidity is summarized in table 2 .

TABLE 2. Change in balance indication in micrograms for each 1-percent change in relative humidity

\begin{tabular}{|c|c|c|c|c|}
\hline Balance & A & B & $\mathrm{C}$ & $\mathrm{D}$ \\
\hline $\begin{array}{l}\text { As received } \\
\text { After cleaning }\end{array}$ & a 2.0 & $\begin{array}{l}\text { Off scale } \ldots \\
0.8\end{array}$ & $\begin{array}{l}8.2 \\
2.8\end{array}$ & Variable. $^{\mathrm{a}}$ \\
\hline
\end{tabular}

a The parts of these balances were not cleaned.

\section{Conclusions}

The results of the investigation establish that the use of hygroscopic materiais causes balances to be sensitive to changes in relative humidity. In particular, lacquer on balance parts introduces large variations in indication as does the accumulation of foreign material on the live parts of the balance.

In balances where the surface areas on the two sides of the balance are unequal, adsorption of moisture is a cause of change. Uncompensated differences in the coefficients of adsorption by different materials in a balance also produce variations.

Most balances are affected by changes in relative humidity, but the effect varies from balance to balance and is unpredictable.

Insofar as possible, hygroscopic materials should not be used in the construction of precision balances. Where hygroscopic materials must be used, it is necessary to compensate for their effect on the performance of the balance.

In the design of precision balances, account should be taken of the adsorption of moisture on the surfaces of their parts. It is important that the adsorption characteristics of the balance parts on either side of the fulcrum knife edge be the same and that the total adsorption on the two sides be equal. If the amount of moisture on both sides of the balance is the same and the rates of change are equal, then change in the relative humidity will not seriously affect the performance of the balance even though the total amount of moisture may be quite large.

With a balance of good design and construction the variation of relative humidity within a narrow range may be disregarded, because it has here been shown that the effect of the variation can be made so small as to be negligible. This point should be reproved with every high-precision balance when first put into service and at regular, if rare, intervals.

The author acknowledges the advice and cooperation of the National Bureau of Standards staff members: Lloyd B. Macurdy, Chief, Mass Unit, Horace A. Bowman, Physicist, and H. Steffen Peiser, Chief, Mass and Scale Section. 